\title{
TAX COMPETITION, EXcludABle Public GoOdS AND USER CHARGES
}

\author{
BERND HUBER \\ MARCO RUNKEL
}

CESIFO WORKING PAPER NO. 1172

CATEgORY 1: PUBlic FinANCE

APRIL 2004

An electronic version of the paper may be downloaded
- from the SSRN website: $\quad w w w . S S R N . c o m$
- from the CESifo website: $\quad w w w . C E S i f o . d e$ 


\title{
TAX COMPetition, ExCludable Public Goods AND USER CHARGES
}

\begin{abstract}
This paper provides an economic explanation for the increasing reliance of the state on revenue from user charges on excludable public goods. We develop a model with many identical countries. The government of each country levies a capital tax on the domestic production sector and supplies an excludable public good to heterogeneous households. Under immobile capital, the price on the public good is zero. Under mobile capital, in contrast, the countries engage in tax competition and each country chooses a strictly positive price on the public good. With quasi-linear preferences, the reliance on user charges is shown to increase as tax competition becomes more intensive.
\end{abstract}

JEL classification: H41, H73, H77.

Keywords: excludable public goods, tax competition.

\author{
Bernd Huber \\ University of Munich \\ Department of Economics \\ Ludwigstr. 28, Vgb., III \\ 80539 Munich \\ Germany \\ huber.sekretariat@lrz.uni-muenchen.de
}

\author{
Marco Runkel \\ University of Munich \\ Department of Economics \\ Ludwigstr. 28, Vgb., III \\ 80539 Munich \\ Germany \\ marco.runkel@lrz.uni-muenchen.de
}




\section{Introduction}

For many public goods, potential users can be excluded from consumption, if they are not willing to pay the user charge or user fee. Examples for such excludable public goods include highways, schools, universities, national parks and television programs. The supply of these goods is attractive for the government since the user charge offers an additional source of revenue. In the US, for example, it is common that state and local governments levy user charges for public education on the primary or secondary level (Wassmer and Fisher 2002). Students of public universities have to pay tuition fees, not only in the US (Canton 2002). Moreover, almost all European countries run public broadcasting stations which are often financed by user fees (O'Hagan and Jennings 2003). Another example is road pricing which has a long tradition in Europe and which the European Commission plans to intensify (European Commission 2001).

In most countries, taxes still account for the largest part of government revenue. But the reliance on user charges is important as well. Table 1 provides evidence from the US. The reliance on charges is the highest on the local level where more than $15 \%$ of general

Table 1: US government reliance on current charges by percentage of general revenue

\begin{tabular}{ccccccc}
\hline Fiscal year & $\mathbf{1 9 7 6 - 1 9 7 7}$ & $\mathbf{1 9 8 1 - 1 9 8 2}$ & $\mathbf{1 9 8 6 - 1 9 8 7}$ & $\mathbf{1 9 9 1 - 1 9 9 2}$ & $\mathbf{1 9 9 6 - 1 9 9 7}$ & $\mathbf{2 0 0 0 / 2 0 0 1}$ \\
\hline Federal & 8.8 & 9.3 & 11.5 & 10.5 & n.a. & n.a. \\
State & 7.1 & 6.4 & 7.6 & 8.7 & 8.5 & 8.9 \\
Local & 10.7 & 11.4 & 13.2 & 14.6 & 15.9 & 15.3 \\
\hline
\end{tabular}

Source: Wassmer and Fisher (2002, p. 88); US Department of Commerce, Bureau of Census

revenue currently stem from user charges. At all levels of government, the importance of user charges significantly increased over the past 30 years. ${ }^{1}$ Of course, these figures include not only revenue from public goods, but also from publicly provided private goods like e.g. water or electric power supply. But we find similar evidence if we focus on selected governmental services which have substantial public good properties. For example, on the local level in the US the revenue from user charges on parks and

\footnotetext{
${ }^{1}$ Under broader definitions of user charges, estimations for state and local governments in the fiscal year 1986-87 even range from 22\% (Tannenwald 1990) up to $35 \%$ (Netzer 1992, Downing 1992).
} 
recreation activities as a percentage of expenditures on these goods increased from $14.1 \%$ in 1962 to $23.4 \%$ in 1989 . For highways and parking this ratio even raised from $14.0 \%$ to $35.5 \%$ (Netzer 1992).

One economic rationale for user charges (or prices) on public goods are externalities caused by the consumption of these goods. Most importantly, public goods are often subject to congestion. The limited capacity and the use of one consumer generate time or opportunity cost to other consumers. Such congestion externalities are especially relevant for highways and universities. They cause an inefficiently high consumption of the public good which can be corrected for by user fees (e.g. Oakland 1987). Environmental pollution is a further kind of externality which may justify user charges. Such an argument is often applied to road pricing (e.g. Calthrop and Proost 1998).

This paper presents another economic explanation of the widespread use of prices on public goods, namely (capital) tax competition among countries. We develop a model of a world economy with many identical countries. The government of each country levies a unit tax on capital input of the domestic production sector. Capital is inelastically supplied by households. Moreover, the government provides a public good to households which differ in their preferences for this good. The public good is assumed to be excludable. Thus, the government has to decide not only about the quantity of the good, but also whether households should be charged with a price or whether consumption of the public good should be for free. If a positive price is charged, households have to decide how much of the public good they want to consume.

Within this framework, we investigate the policy chosen by the welfare-maximizing government of a representative country under alternative assumptions regarding capital mobility. Under immobile capital, the government sets the price on the public good equal to zero. The reason is that the capital tax is then effectively a lump sum tax which ensures an efficient provision of the public good according to the Samuelson rule. In contrast, under mobile capital the capital tax becomes a distortionary tax. The countries engage in tax competition since an increase in the domestic tax rate leads to an outflow of capital. The government then imposes a positive price on the public good since this generates additional revenue such that the underprovision (which would occur for a zero price or, equivalently, for pure, nonexcludable public goods) is 
mitigated. For the special case of quasi-linear preferences, we also show that the public good price and the reliance on user charges increase if tax competition is intensified. Since empirical evidence suggests that capital has become more mobile over the past decades, our results can help to explain the above-mentioned widespread and increasing use of prices on public goods.

Since the seminal work of Zodrow and Mieszkowski (1986), a vast literature on tax competition has been developed. Recent contributions are, for example, Huber (1999) or Mintz and Smart (2004). Surveys can be found in Wilson (1999), Fuest et al. (2003) and Wilson and Wildasin (2004). To the best of our knowledge, however, an analysis of tax competition in the presence of excludable public goods is not available. There is also a steadily growing literature on excludable public goods. See, for example, Brito and Oakland (1980), Burns and Walsh (1981), Fraser (1996), Schmitz (1997) and Cremer and Laffont (2003). But this line of literature does not account for tax competition. Related to our study is the paper of Blomquist and Christiansen (2001). They show that the price on an excludable public good may be positive if the government employs a nonlinear income tax under asymmetric information. Our approach is different since in our model tax competition is responsible for positive prices on public goods.

The paper is organized as follows. In Section 2, we describe the basic model. Section 3 investigates the government's policy under immobile capital. In Section 4, we turn to the case of mobile capital and tax competition. Section 5 derives further results under the additional assumption of quasi-linear preferences and Section 6 concludes.

\section{The Model}

We consider a model of a world economy with many identical countries. A representative country is populated by $n \geq 1$ households which are described in more detail below. For the moment, we note that each household is endowed with $\bar{k}>0$ units of capital which it inelastically supplies at the capital market. In addition, each household owns a fraction of $1 / n$th of the representative firm in the country. The firm's production technology is described by $X(k)$ where $k>0$ denotes the firm's capital stock. The production function $X$ is twice continuously differentiable and satisfies $X^{\prime}(k)>0$ and $X^{\prime \prime}(k)<0$. The government of the representative country levies a unit $\operatorname{tax} \tau>0$ on 
the firm's capital input. Denoting the interest rate in the representative country by $r>0$, profit of the production firm is

$$
\Pi(k)=X(k)-(r+\tau) k
$$

The firm takes as given the tax rate and the interest rate and chooses the capital stock in order to maximize profit. The first-order condition $X^{\prime}(k)=r+\tau$ determines the firm's demand for capital as a function of the tax rate and the interest rate. Let this capital demand be denoted by $K(r+\tau)$. Differentiating the first-order condition yields $K^{\prime}=1 / X^{\prime \prime}<0$. An increase in $\tau$ or $r$ thus reduces the firm's capital demand.

We will consider two different versions of capital mobility. As a benchmark, attention is paid to the case where capital is totally immobile. The capital supply in each country is then fixed at $n \bar{k}$. Equilibrium at the representative country's capital market requires $n \bar{k}=K(r+\tau) \equiv k^{*}$ where $k^{*}$ stands for the equilibrium amount of capital. Since the capital supply is fixed at $n \bar{k}$, an increase in the domestic tax rate induces a fall of the domestic interest rate in order to maintain the capital market equilibrium. Formally, the equilibrium condition implies $d k^{*} / d \tau=0$. Under immobile capital, the capital tax therefore represents a lump sum tax which leaves undistorted the production decision of the representative firm.

In the second case, capital is mobile. From an individual country's perspective, the capital tax then becomes a source-based tax on capital and the countries play a tax competition game: Denoting by $r^{w}$ the world interest rate, interest arbitrage under capital mobility implies $r=r^{w}$, i.e. the domestic interest rate equals the world interest rate. We assume that each country is sufficiently small such that it acts as a price taker on the world capital market and takes as given the world interest rate. The equilibrium capital stock in the representative country is then determined by $k^{*}=K\left(r^{w}+\tau\right)$ and an increase in the domestic tax rate no longer induces a reduction in the domestic interest rate. Instead, the tax increase ceteris paribus leads to an outflow of capital amounting to $d k^{*} / d \tau=K^{\prime}<0$. We concentrate on a symmetric equilibrium of the tax competition game. Of course, the symmetry assumption implies that, in equilibrium, the capital stock in each country equals $n \bar{k}$, as under immobile capital.

Total available resources in the representative country consist of the output of the domestic firm and the sum of capital endowments plus interest payments. These avail- 
able resources may be used to produce a private good and a public good. We assume linear production technologies. Units are chosen such that producing one unit of the private good requires exactly one unit of the available resources and producing one unit of the public good uses up $\alpha>0$ units of the available resources. The parameter $\alpha$ therefore reflects the marginal production cost of the public good.

Consider now the households in the representative country. Each household earns income from the profit of the firm and from the endowment with capital. For simplicity, we ignore other sources of income. Total income of a household then amounts to

$$
Y(\tau)=\frac{\Pi\left(k^{*}\right)}{n}+(1+r) \bar{k}
$$

where $k^{*}=n \bar{k}$ under immobile capital while $k^{*}=K\left(r^{w}+\tau\right)$ and $r=r^{w}$ under mobile capital. The first term in (1) is the income from the household's share of the firm's profit and the second term stands for capital endowment plus interest payments. Total income is the same for all households. Differentiating yields $Y^{\prime}(\tau)=-k^{*} / n<0$ where in case of mobile capital we employed the first-order condition of profit maximization.

While all households have the same income, they differ with respect to their preferences for the public good. These preferences constitute the type of a household and are expressed by the parameter $\beta$. Higher values of $\beta$ indicate stronger preferences. The parameter $\beta$ is distributed over the interval $[0, \bar{\beta}]$ with the distribution function $F(\beta)$ and the density function $f(\beta)$ which satisfy $F(0)=0, F(\bar{\beta})=1$ and $f(\beta)=d F(\beta) / d \beta$. The utility of a household of type $\beta$ is given by the twice continuously differentiable and quasi-concave utility function $U(c, g, \beta)$ where $c>0$ denotes consumption of the private good and $g \geq 0$ is the quantity of the public good. Marginal utility of the private good is positive and non-increasing $\left(U_{c}>0, U_{c c} \leq 0\right)$. Marginal utility of the public good is positive and strictly decreasing $\left(U_{g}>0, U_{g g}<0\right)$. Stronger preferences for the public good mean that the marginal utility of the public good increases while the marginal utility of the private good is non-decreasing, i.e. the cross derivatives of the utility function satisfy $U_{g \beta}>0$ and $U_{c \beta} \leq 0$. Both goods are assumed to be normal.

The government supplies a quantity $g_{s}>0$ of the public good. The public good is nonrival in consumption, but we assume that (costless) exclusion is possible. The government may therefore charge a user fee or price $p$ per unit of the public good. An individual household is allowed to consume only those units which she has paid 
for. Using the private good as numeraire, the household's budget constraint is given by $y=c+p g$ where total income $y=Y(\tau)$ is defined in (1). Taking as given this income and the price of the public good, the household has to decide how much of the public good she wants to consume. The maximum amount the household can consume is $g_{s}$, the quantity supplied by the government. Taking into account this constraint, the utility maximization problem of a type $\beta$ household may be written as

$$
\max _{g} U[y-p g, g, \beta] \quad \text { s.t. } \quad g \leq g_{s} \text {. }
$$

The constraint $g \leq g_{s}$ may or may not be binding depending on the household's preferences for the public good. In case the constraint is binding, the household is effectively rationed, i.e. at price $p$ she would like to consume more than $g_{s}$. Such a household is said to be quantity-rationed. In contrast, if the constraint is not binding, the household's demand falls short of the government's supply. The household is then said to be price-excluded since she consumes less than the total supply $g_{s}$.

Let us first consider the solution of the utility maximization problem (2) when the household is price-excluded. Since the constraint $g \leq g_{s}$ is not binding in this case, the first-order condition for a utility maximum can be rearranged to

$$
\operatorname{MRS}^{p}(y, p, \beta)=\frac{U_{g}(y-p g, g, \beta)}{U_{c}(y-p g, g, \beta)}=p
$$

where the marginal rate of substitution $\mathrm{MRS}^{p}$ reflects the household's marginal willingness-to-pay for the public good. Equation (3) states that this willingness-to-pay equals the price of the public good. It implicitly defines the household's uncompensated demand for the public good as a function of the price, the income and the preference parameter. This function is denoted by $G(y, p, \beta)$. Since we assume the public good to be normal, it follows $G_{y} \geq 0$ and, by the Slutzky decomposition, $G_{p}=G_{p}^{h}-G G_{y}<0$ where $G_{p}^{h}<0$ is the derivative of the compensated demand function with respect to the price of the public good. Moreover, applying the implicit function theorem to (3) yields $G_{\beta}=-\left(U_{g \beta}-p U_{c \beta}\right) / \Delta>0$ with $\Delta=U_{g g}+p^{2} U_{c c}-2 p U_{c g}<0$ due to the second-order condition of utility maximization. The positive sign of $G_{\beta}$ confirms the intuitive result that the demand for the public good is the larger, the larger are the preferences for this good. The indirect utility function of a price-excluded household is

$$
V^{p}(y, p, \beta)=U[y-p G(y, p, \beta), G(y, p, \beta), \beta] .
$$


It satisfies the standard properties $V_{y}^{p}(\cdot)=U_{c}(\cdot)>0, V_{p}^{p}(\cdot)=-G(\cdot) U_{c}(\cdot)<0$ and Roy's identity $G(\cdot)=-V_{p}^{p}(\cdot) / V_{y}^{p}(\cdot)$.

Consider next the solution of the utility maximization problem (2) when the household is quantity-rationed. In this case, the optimal demand for the public good equals $g_{s}$ independent of the household's type. Since the constraint in (2) is binding, the first-order condition for the utility maximum can be written as

$$
\operatorname{MRS}^{q}\left(y, p, g_{s}, \beta\right)=\frac{U_{g}\left(y-p g_{s}, g_{s}, \beta\right)}{U_{c}\left(y-p g_{s}, g_{s}, \beta\right)}=p+\frac{\lambda}{U_{c}\left(y-p g_{s}, g_{s}, \beta\right)}>p,
$$

where $\lambda>0$ is the Lagrange multiplier associated with the constraint $g \leq g_{s}$. Equation (4) confirms that a quantity-rationed household is willing to pay more for the public good than she actually has to pay. Her indirect utility function is

$$
V^{q}\left(y, p, g_{s}, \beta\right)=U\left[y-p g_{s}, g_{s}, \beta\right]
$$

We obtain $V_{y}^{q}(\cdot)=U_{c}(\cdot)>0, V_{p}^{q}(\cdot)=-g_{s} U_{c}(\cdot)<0$ and $V_{g}^{q}(\cdot)=V_{y}^{q}(\cdot)\left[\operatorname{MRS}^{q}(\cdot)-\right.$ $p]>0$. Note that Roy's identity is true also for a quantity-rationed household since $-V_{p}^{q}(\cdot) / V_{y}^{q}(\cdot)=g_{s}$.

Depending on their preferences for the public good, households can be either priceexcluded or quantity-rationed. The marginal household has preferences $\beta^{m}$ such that her marginal willingness-to-pay for the public good supply $g_{s}$ equals the price $p$, i.e. $\operatorname{MRS}^{q}\left(y, p, g_{s}, \beta^{m}\right)=p$ or, equivalently, $V_{g}^{q}\left(y, p, g_{s}, \beta^{m}\right)=0$. The unrestricted public good demand of this household is just equal to the quantity supplied so that

$$
G\left(y, p, \beta^{m}\right)=g_{s}
$$

Equation (5) implicitly defines the marginal household as a function of the income, the price and the supplied quantity of the public good. Formally, we have $\beta^{m}=B\left(y, p, g_{s}\right)$ with $B_{y}=-G_{y} / G_{\beta} \leq 0, B_{p}=-G_{p} / G_{\beta}>0$ and $B_{g}=1 / G_{\beta}>0$. Moreover, (5) together with $G_{\beta}>0$ implies that $G(y, p, \beta) \lesseqgtr g_{s}$ if and only if $\beta \lesseqgtr \beta^{m}$. Hence, all households with public good preferences in the interval $\left[0, \beta^{m}\right]$ are price-excluded while households with public good preferences in the interval $\left[\beta^{m}, \bar{\beta}\right]$ belong to the group of quantity-rationed households. If consumption of the public good is for free, we obtain $\beta^{m}=B\left(y, 0, g_{s}\right)=0$ since the first-order condition of utility maximization implies $\lambda=U_{g}(\cdot)>0$ for all $\beta \in[0, \bar{\beta}]$. All households are then quantity-rationed. 
Let us now turn to the government of the representative country. Social welfare in the country is given by the Utilitarian welfare function

$$
W\left(\tau, p, g_{s}\right)=n \int_{0}^{\beta^{m}} V^{p}(y, p, \beta) d F(\beta)+n \int_{\beta^{m}}^{\bar{\beta}} V^{q}\left(y, p, g_{s}, \beta\right) d F(\beta),
$$

with $\beta^{m}=B\left(y, p, g_{s}\right)$ and $y=Y(\tau)$. The two terms in the welfare function (6) reflect the utility of the price-excluded and the quantity-rationed households. The governmental budget constraint reads

$$
\alpha g_{s}=n p \int_{0}^{\beta^{m}} G(y, p, \beta) d F(\beta)+n p g_{s}\left[1-F\left(\beta^{m}\right)\right]+\tau k^{*},
$$

with $k^{*}=n \bar{k}$ under immobile capital and $k^{*}=K\left(r^{w}+\tau\right)$ under mobile capital. The LHS of (7) equals the government's expenditures on the public good. The government's revenue is reflected by the three terms on the RHS. They represent the payments of price-excluded households for the public good, the payments of the quantity-rationed households for the public good and the tax revenue, respectively. The government of the representative country chooses the tax rate on capital and the price and quantity of the public good such that these variables maximize social welfare (6) subject to the budget constraint (7). The Lagrangean for this problem is

$$
\begin{aligned}
L= & n \int_{0}^{\beta^{m}} V^{p}(y, p, \beta) d F(\beta)+n \int_{\beta^{m}}^{\bar{\beta}} V^{q}\left(y, p, g_{s}, \beta\right) d F(\beta) \\
& +\mu\left[n p \int_{0}^{\beta^{m}} G(y, p, \beta) d F(\beta)+n p g_{s}\left[1-F\left(\beta^{m}\right)\right]+\tau k^{*}-\alpha g_{s}\right],
\end{aligned}
$$

where the Lagrange multiplier $\mu>0$ represents the marginal cost of public funds. We assume an interior solution with respect to the capital tax and the supplied quantity of the public good, but allow for corner solutions with respect to the price of the public good. The first-order conditions of welfare maximization can then be written as

$$
\begin{gathered}
L_{\tau}=-k^{*}\left[\int_{0}^{\beta^{m}} V_{y}^{p} d F+\int_{\beta^{m}}^{\bar{\beta}} V_{y}^{q} d F\right]+\mu k^{*}\left[1-p \int_{0}^{\beta^{m}} G_{y} d F-\frac{\tau \varepsilon}{r+\tau}\right]=0, \\
L_{p}=n \int_{0}^{\beta^{m}} V_{p}^{p} d F+n \int_{\beta^{m}}^{\bar{\beta}} V_{p}^{q} d F+\mu\left[n \int_{0}^{\beta^{m}}\left(G+p G_{p}\right) d F+n g_{s}\left[1-F\left(\beta^{m}\right)\right]\right] \leq 0, \\
p L_{p}=0,
\end{gathered}
$$




$$
\begin{gathered}
L_{g}=n \int_{\beta^{m}}^{\bar{\beta}} V_{g}^{q} d F+\mu\left[n p\left[1-F\left(\beta^{m}\right)\right]-\alpha\right]=0, \\
L_{\mu}=n p \int_{0}^{\beta^{m}} G d F+n p g_{s}\left[1-F\left(\beta^{m}\right)\right]+\tau k^{*}-\alpha g_{s}=0,
\end{gathered}
$$

where, for notational convenience, we suppressed the arguments of the functions when there is no risk of misunderstanding. $\varepsilon=-\left[d k^{*} / d(r+\tau)\right] \cdot(r+\tau) / k^{*} \geq 0$ is the elasticity of the equilibrium capital input with respect to $r+\tau$. This elasticity may be interpreted as a measure of the degree of (outward) capital mobility. It is assumed to be non-decreasing in $r+\tau$, i.e. $d \varepsilon / d(r+\tau) \geq 0 .{ }^{2}$ With the help of (8) to (12) we now investigate the solution to the government's welfare maximization problem under different assumptions regarding capital mobility. ${ }^{3}$

\section{Immobile Capital}

Under immobile capital, the equilibrium capital stock of the representative country does not depend on the tax rate. Formally, we have $d k^{*} / d \tau=0$ and $\varepsilon=0$. To characterize the solution of the government's problem in this case, we ask whether the welfare maximum is reached if the government sets the price of the public good equal to zero. Under a zero price, the marginal household $\beta^{m}$ is zero, too, and all households are quantity-rationed. The first-order condition (8) then implies $\mu=\int_{0}^{\bar{\beta}} V_{y}^{q} d F$, i.e. the marginal cost of public funds equals the mean of the households' marginal utility of income. Inserting this and $V_{g}^{q}=V_{y}^{q} \mathrm{MRS}^{q}$ into (11) yields

$$
n \int_{0}^{\bar{\beta}} V_{y}^{q} \operatorname{MRS}^{q} d F=\alpha \int_{0}^{\bar{\beta}} V_{y}^{q} d F .
$$

\footnotetext{
${ }^{2}$ In the special case of quasi-linear preferences which we consider in Section 5, this assumption is sufficient for the welfare function to be concave in the tax rate $\tau$. The assumption is satisfied by a large class of production functions. For example, if $X(k)=k^{\gamma}$, then $\varepsilon=1 /(1-\gamma)$ and $d \varepsilon / d(r+\tau)=0$. For $X(k)=\ln (k+1)$ we obtain $\varepsilon=1 /(1-r-\tau)$ and $d \varepsilon / d(r+\tau)=1 /(1-r-\tau)^{2}>0$.

${ }^{3}$ It is straightforward to show that in the welfare optimum $g_{s} \leq G(y, p, \bar{\beta})$ so that $\beta^{m}$ lies in the interval $[0, \bar{\beta}]$. Suppose the opposite, i.e. $g_{s}>G(y, p, \bar{\beta})$ or, equivalently, $g_{s}>G(y, p, \beta)$ for all $\beta \in[0, \bar{\beta}]$. All households are on their demand curve for the public good. But the government may then relax its budget constraint by reducing the public good supply $g_{s}$. For a given tax rate, the price of the public good may be lowered with the consequence that utility of all households increases according to $V_{p}^{p}<0$. The reduction of $g_{s}$ does not have a welfare effect since $V^{p}$ is independent of $g_{s}$.
} 
For the time being, suppose the marginal utility of the private good does not depend on the preference parameter $\beta$, i.e. $U_{c \beta} \equiv 0$. The marginal utility of income, $V_{y}^{q}=U_{c}$, is then independent of the household's type and (13) simplifies to

$$
n \int_{0}^{\bar{\beta}} \operatorname{MRS}^{q} d F=\alpha .
$$

This is the familiar Samuelson rule stating that the sum of the households' marginal willingness-to-pay just offsets the marginal cost of the public good. It is well known that this condition characterizes the first-best optimum chosen by a benevolent social planner, and it is straightforward to show that this is true also in our model with an excludable public good (see the appendix). Hence, the best strategy the government can pursue in case of immobile capital and $U_{c \beta} \equiv 0$ is to finance its expenditures solely by the capital tax and to supply the public good free of charge. Indicating welfare-maximizing values by a star, this result is summarized in

Proposition 1. Suppose capital is immobile and $U_{c \beta} \equiv 0$. Then the government chooses $p^{*}=0$ and $\tau^{*}=\alpha g_{s}^{*} / n \bar{k}>0$ where the public good supply $g_{s}^{*}$ is determined by the Samuleson rule (14).

The intuition of Proposition 1 is as follows. If capital is immobile, the countries do not engage in tax competition. The domestic capital stock is not affected by tax changes and the tax leaves undistorted the production decision of the domestic firm. The capital tax is therefore effectively a lump sum tax which on its own ensures an efficient supply of the public good according to the Samuelson rule. This is the reason why no additional charge on the consumption of the public good is needed.

It should be noted that Proposition 1 cannot be generalized to the case where the marginal utility of the private good is strictly decreasing in the preference parameter $\left(U_{c \beta}<0\right)$. Implicitly contained in the Utilitarian welfare function (6) is a distributional goal. The government wants to equalize the marginal utility of income across households. If $U_{c \beta} \equiv 0$ and $p=0$, this goal is realized since all households are quantityrationed and the marginal utility of income, $V_{y}^{q}=U_{c}$, does not depend on the household type $\beta$. But if $U_{c \beta}<0$, then the marginal utility of income differs between households even if the price of the public good is zero and all households are quantity-rationed. In this case, it can be shown that setting $p=0$ results in an underprovision of the 
public good relatively to the Samuelson rule. ${ }^{4}$ It may then be welfare-enhancing for the government to levy a positive price on the public good in order to overcome this underprovision. For $U_{c \beta}<0$, the optimal price of the public good may therefore be positive even under immobile capital.

\section{Mobile Capital}

Suppose now that capital is mobile. The equilibrium capital stock in the representative country is then $k^{*}=K\left(r^{w}+\tau\right)$. The countries engage in tax competition since an increase in the domestic tax rate ceteris paribus reduces the capital stock by $d k^{*} / d \tau=K^{\prime}<0$. The elasticity of capital is strictly positive $(\varepsilon>0)$. In case of pure (nonexcludable) public goods, it is well known from the literature that such tax competition typically leads to an equilibrium with inefficiently low tax rates and an underprovision of the public good. This result can be proven also in our model: If exclusion is not feasible, the price of the public good is fixed at zero. The welfaremaximizing policy is then determined by (8), (11), (12) and $p=0$. By conducting a comparative static analysis, it is straightforward to show that an increase in $\varepsilon$ from zero (no tax competition) to a positive value (tax competition) reduces the optimal tax rate $\tau^{*}$ and the optimal public good supply $g_{s}^{*} .^{5}$

As preparation for the subsequent analysis, we now investigate how this underprovision result is affected if the price is parametrically moved from zero (pure public good) to a positive value (excludable public good). The result is contained in

Lemma 1. Suppose capital is mobile and $p$ is equal to zero. A marginal increase in $p$ then reduces $\tau^{*}$ and increases $g_{s}^{*}$.

Proof: If $p$ is treated as parameter, the welfare-maximizing policy is determined by (8), (11) and (12). The impact of $p$ can then be obtain by a comparative static analysis

\footnotetext{
${ }^{4}$ To be more specific, $U_{c \beta}<0$ implies that $V_{y}^{q}=U_{c}$ depends on $\beta$. Equation (13) can then be rearranged to $n \int_{0}^{\bar{\beta}} \operatorname{MRS}^{q} d F=\alpha-n \cdot \operatorname{cov}\left[V_{y}^{q}, \operatorname{MRS}^{q}\right] / \overline{V_{y}^{q}}$ where $\overline{V_{y}^{q}}=\int_{0}^{\bar{\beta}} V_{y}^{q} d F$ is the average marginal utility of income. $V_{y \beta}^{q}=U_{c \beta}<0$ and $\operatorname{MRS}_{\beta}^{q}=\left(U_{g \beta} U_{c}-U_{c \beta} U_{g}\right) / U_{c}^{2}>0$ imply that the covariance in this expression is negative. Hence, there is an underprovision relatively to the Samuelson rule.

${ }^{5}$ We skip the formal proof of this result because it is standard in the tax competition literature. See the articles already referred to in the introduction.
} 
of these conditions. Totally differentiating and applying Cramer's rule yields

$$
\begin{aligned}
\frac{d \tau^{*}}{d p} & =\frac{L_{\tau p} L_{g \mu}^{2}+L_{p \mu} L_{\tau \mu} L_{g g}-L_{\tau \mu} L_{p g} L_{g \mu}-L_{\tau g} L_{g \mu} L_{p \mu}}{|\mathcal{H}|} \\
\frac{d g_{s}^{*}}{d p} & =\frac{L_{p g} L_{\tau \mu}^{2}+L_{p \mu} L_{g \mu} L_{\tau \tau}-L_{\tau g} L_{p \mu} L_{\tau \mu}-L_{\tau p} L_{g \mu} L_{\tau \mu}}{|\mathcal{H}|}
\end{aligned}
$$

where we have used $L_{\mu \mu}=0$ and where $|\mathcal{H}|$ is the determinant of the bordered Hessian of $L_{\tau}=L_{g}=L_{\mu}=0$. It has to be positive due to the second-order conditions of welfare maximization. Computing the second derivatives of the Lagrangean and evaluating them at $p=0$ yields

$$
\begin{gathered}
L_{\tau \tau}=\frac{k^{* 2}}{n} \int_{0}^{\bar{\beta}} V_{y y}^{q} d F-\frac{\mu k^{*}}{r^{w}+\tau}\left[\frac{\varepsilon r^{w}}{r^{w}+\tau}+\tau \frac{d \varepsilon}{d \tau}\right], \\
L_{\tau p}=-k^{*} \int_{0}^{\bar{\beta}} V_{y p}^{q} d F, \quad L_{\tau g}=-k^{*} \int_{0}^{\bar{\beta}} V_{y g}^{q} d F, \quad L_{\tau \mu}=k^{*}-\frac{\tau \varepsilon k^{*}}{r^{w}+\tau}, \\
L_{p g}=n \int_{0}^{\bar{\beta}} V_{p g}^{q} d F+\mu n, \quad L_{p \mu}=n g_{s}, \quad L_{g g}=n \int_{0}^{\bar{\beta}} V_{g g}^{q} d F, \quad L_{g \mu}=-\alpha,
\end{gathered}
$$

where we used $L_{\tau}=0$ to simplify $L_{\tau \tau}$. From the definition of $V^{q}$, we obtain

$$
\begin{gathered}
V_{y}^{q}=U_{c}>0, \quad V_{y y}^{q}=U_{c c} \leq 0, \quad V_{y p}^{q}=-g_{s} U_{c c} \geq 0, \quad V_{y g}^{q}=U_{c g}-p U_{c c} \geq 0 \\
V_{p g}^{q}=-U_{c}-g_{s} V_{y g}^{q}<0, \quad V_{g g}^{q}=p^{2} U_{c c}-2 p U_{c g}+U_{g g}<0 .
\end{gathered}
$$

The sign of $V_{g g}^{q}$ follows from the second-order condition of individual utility maximization and the sign of $V_{y g}^{q}$ is due to $G_{y} \geq 0$. From (17) to (19) we then obtain $L_{\tau p} \leq 0, L_{\tau g} \leq 0, L_{p \mu}>0, L_{g g}<0$ and $L_{g \mu}<0 . L_{\tau \mu}>0$ follows from the firstorder condition (8). Equation (9) together with $p=0$ implies $\mu=\int_{0}^{\bar{\beta}} U_{c} d F$ and $L_{p g}=-n g_{s} \int_{0}^{\bar{\beta}} V_{y g}^{q} d F \leq 0$. Taking into account all these derivatives of the Lagrangean in (15) immediately proves $d \tau^{*} / d p<0$. To check the sign of (16), note that

$$
\begin{gathered}
L_{p g} L_{\tau \mu}^{2}-L_{\tau g} L_{p \mu} L_{\tau \mu}=\frac{n g_{s} \tau \varepsilon k^{*} L_{\tau \mu}}{r^{w}+\tau} \int_{0}^{\bar{\beta}} V_{y g}^{q} d F \geq 0 \\
L_{p \mu} L_{g \mu} L_{\tau \tau}-L_{\tau p} L_{g \mu} L_{\tau \mu}=\frac{\alpha \tau \varepsilon k^{* 2}}{r^{w}+\tau} \int_{0}^{\bar{\beta}} V_{y p}^{q} d F+\frac{\alpha n g_{s} \mu k^{*}}{r^{w}+\tau}\left[\frac{\varepsilon r^{w}}{r^{w}+\tau}+\tau \frac{d \varepsilon}{d \tau}\right]>0 .
\end{gathered}
$$

Remember that $d \varepsilon / d \tau \geq 0$. Inserting (20) and (21) into (16) yields $d g_{s}^{*} / d p>0$. 
Lemma 1 shows that, at the margin, a positive price reduces the welfare-maximizing capital tax rate compared to the case of a zero price or, equivalently, to the case of a pure public good. Hence, the exclusion property of the public good aggravates the tendency to undertaxation. However, the positive price also generates additional revenue for the government, and this additional revenue more than outweighs the revenue loss caused by the decline in the tax rate. At the margin, exclusion therefore mitigates the underprovision of public goods.

With this insight, it is straightforward to answer the question whether capital mobility induces the government of the representative country to charge households with a positive price for the public good. We obtain

Proposition 2. Suppose capital is mobile. Then the government sets $p^{*}>0$.

Proof: Suppose the opposite is true, i.e. $p^{*}=0$. Then $\beta^{m}=0$ and the first-order condition (8) yields

$$
\mu=\frac{1}{1-\tau \varepsilon /\left(r^{w}+\tau\right)} \int_{0}^{\bar{\beta}} V_{y}^{q} d F .
$$

Note that $1-\tau \varepsilon /\left(r^{w}+\tau\right)>0$ according to (8). Inserting (22) into $L_{p}$ from (9) and cancel common terms, we obtain

$$
L_{p}=\frac{n g_{s} \tau \varepsilon}{r^{w}+\tau-\tau \varepsilon} \int_{0}^{\bar{\beta}} V_{y}^{q} d F>0,
$$

where Roy's identity $g_{s}=-V_{p}^{q} / V_{y}^{q}$ has been used. This contradicts the first-order condition (9). It follows $p^{*}>0$.

Proposition 2 states that under mobile capital the government has always an incentive to impose a positive price on the consumption of the public good. In view of Proposition 1 and Lemma 1 the intuition is obvious. Under mobile capital, the capital tax distorts the production decision of the domestic firm and ceteris paribus leads to outflow of capital into the rest of the world. If the price of the public good is set equal to zero or, equivalently, if exclusion is not feasible, the distortionary effect of the capital tax causes an underprovision of the public good. Pricing the public good is an appropriate measure for the government to mitigate this underprovision. It generates additional revenue such that the government may supply more of the public good and, at the same time, further reduce the capital tax. 


\section{Quasi-Linear Preferences}

Proposition 2 is a general result since it holds for all specifications of our model. Unfortunately, a further analysis in the general case is intractable. In what follows, we therefore confine ourselves to the case of quasi-linear preferences. The utility function of household $\beta$ is $U(c, g, \beta)=c+\beta H(g)$ with $H^{\prime}>0$ and $H^{\prime \prime}<0$. For priceexcluded households, the income effect of the public good is then zero, i.e. $G_{y}=0$ and $G_{p}=G_{p}^{h}=1 / \beta H^{\prime \prime}(g)<0$. The indirect utility function of a price-excluded household simplifies to $V^{p}(y, p, \beta)=y-p G(p, \beta)+\beta H[G(p, \beta)]$ implying $V_{y}^{p}=1$ and $V_{p}^{p}=-G$. The indirect utility function of a quantity-rationed household reads $V^{q}\left(y, p, g_{s}, \beta\right)=$ $y-p g_{s}+\beta H\left(g_{s}\right)$ such that $V_{y}^{q}=1, V_{p}^{q}=-g_{s}$ and $V_{g}^{q}=\beta H^{\prime}\left(g_{s}\right)-p=\lambda>0$. The marginal household equals $\beta^{m}=p / H^{\prime}\left(g_{s}\right)$. It is independent of income $\left(B_{y}=0\right)$ and we obtain $B_{p}=1 / H^{\prime}\left(g_{s}\right)>0$ and $B_{g}=-\beta^{m} H^{\prime \prime}\left(g_{s}\right) / H^{\prime}\left(g_{s}\right)>0$.

The main question we want to investigate in this special case is what impact the degree of capital mobility has on the welfare-maximizing policy of the government. As mentioned above, the degree of capital mobility may be measured by the elasticity $\varepsilon$ of equilibrium capital with respect to $r^{w}+\tau$. The larger this elasticity is, the larger is capital mobility. If, for simplicity, $\varepsilon$ is assumed to be a constant, a comparative static analysis of the first-order conditions (8) to (12) yields

Proposition 3. Suppose capital is mobile and preferences are quasi-linear. Then

$$
\frac{d p^{*}}{d \varepsilon}>0, \quad \frac{d \tau^{*}}{d \varepsilon}<0, \quad \frac{d g_{s}^{*}}{d \varepsilon}<0 \quad \text { and } \quad \frac{d \mu^{*}}{d \varepsilon}>0 .
$$

Proof: Totally differentiating the first-order conditions (8) to (12) for $p>0$ and applying Cramer's rule yields

$$
\begin{aligned}
\frac{d p^{*}}{d \varepsilon} & =-\frac{\mu \tau k^{*} L_{\tau \mu}}{\left(r^{w}+\tau\right)|\mathcal{H}|}\left[L_{p g} L_{g \mu}-L_{g g} L_{p \mu}\right], \\
\frac{d \tau^{*}}{d \varepsilon} & =\frac{\mu \tau k^{*}}{\left(r^{w}+\tau\right)|\mathcal{H}|}\left[2 L_{p g} L_{g \mu} L_{p \mu}-L_{p \mu}^{2} L_{g g}-L_{g \mu}^{2} L_{p p}\right], \\
\frac{d g_{s}^{*}}{d \varepsilon} & =\frac{\mu \tau k^{*} L_{\tau \mu}}{\left(r^{w}+\tau\right)|\mathcal{H}|}\left[L_{p p} L_{g \mu}-L_{p g} L_{p \mu}\right], \\
\frac{d \mu^{*}}{d \varepsilon} & =-\frac{\mu \tau k^{*} L_{\tau \mu}}{\left(r^{w}+\tau\right)|\mathcal{H}|}\left[L_{p p} L_{g g}-L_{p g}^{2}\right],
\end{aligned}
$$


where $|\mathcal{H}|$ is the determinant of the bordered Hessian of (8) to (12). It has to be negative due to the second-order conditions of welfare maximization. The negative semi-definiteness of the (unbordered) Hessian of (8) to (12) implies that $d \mu^{*} / d \varepsilon>0$. It remains to determine the signs of (23) to (25). The second derivatives of $L$ are

$$
\begin{gathered}
L_{\tau \tau}=-\frac{\mu k^{*}}{r^{w}+\tau}\left[\frac{\varepsilon r^{w}}{r^{w}+\tau}+\tau \frac{d \varepsilon}{d \tau}\right]<0, \quad L_{\tau p}=L_{\tau g}=0, \\
L_{\tau \mu}=k^{*}-\frac{\tau k^{*}}{r^{w}+\tau}>0, \quad L_{p g}=-\mu n \beta^{m} f\left(\beta^{m}\right)+(\mu-1) n\left[1-F\left(\beta^{m}\right)\right]<0, \\
L_{p p}=(2 \mu-1) n \int_{0}^{\beta^{m}} G_{p} d F+\mu n p \int_{0}^{\beta^{m}} G_{p p} d F+\frac{\mu n f\left(\beta^{m}\right)}{H^{\prime \prime}\left(g_{s}\right)}<0 \\
L_{p \mu}=n \int_{0}^{\beta^{m}}\left(G+p G_{p}\right) d F+n g_{s}\left[1-F\left(\beta^{m}\right)\right]>0, \quad L_{g \mu}=n p\left[1-F\left(\beta^{m}\right)\right]-\alpha<0 \\
L_{g g}=n H^{\prime \prime}\left(g_{s}\right) \int_{\beta^{m}}^{\bar{\beta}} \beta d F+\mu n \beta^{m 2} f\left(\beta^{m}\right) H^{\prime \prime}\left(g_{s}\right)<0, \quad L_{\mu \mu}=0 .
\end{gathered}
$$

The signs of the derivatives $L_{\tau \tau}, L_{p p}$ and $L_{g g}$ follow from the second-order conditions of welfare maximization. The signs of the remaining expressions follow from (8) to (12). Taking into account the second derivatives of the Lagrangean $L$ in (23) to (25) completes the proof of the proposition.

According to Proposition 3, there is a monotonic relationship between the degree of capital mobility, on the one hand, and the optimal capital tax and the optimal price of the public good, on the other hand. If capital becomes more mobile, the government further decreases the already inefficiently low tax rate. In this sense, tax competition further intensifies. At the same time, the government generates additional revenue by increasing the price on the public good. The additional revenue is used to compensate the loss in tax revenue. However, Proposition 3 also shows that an increase in the degree of capital mobility always induces a decline in the public good supply. Hence, the additional revenue from the increased price on the public good only partly outweighs the loss in tax revenue and never leads to an overprovision of the public good. This may also seen from the marginal cost of public funds which increases if tax competition becomes more fierce.

The intuition of this result can further be explained by deriving a modified Samuel- 
son rule. Under quasi-linear preferences, the first-order condition (11) becomes

$$
\int_{0}^{\bar{\beta}} \beta H^{\prime}\left(g_{s}^{*}\right) d F=\alpha+\left(\mu^{*}-1\right) \alpha-\left(\mu^{*}-1\right) n p^{*}\left[1-F\left(\beta^{m}\right)\right]+\int_{0}^{\beta^{m}} \beta H^{\prime}\left(g_{s}^{*}\right) d F,
$$

where $\mu^{*}=1 /\left[1-\tau \varepsilon /\left(r^{w}+\tau\right)\right]>1$ from (8) and $\varepsilon>0$. Equation (27) differs from the Samuleson rule in the three last terms on the RHS. The term $\left(\mu^{*}-1\right) \alpha$ represents the tax distortion cost under mobile capital. It is positive and, thus, tends to an underprovision of the public good. The term $-\left(\mu^{*}-1\right) n p^{*}(1-F)$ indicates that the revenue from the user charge on the public good is used to relax the governmental budget constraint and to reduce the tax distortion cost. It tends to an overprovision of the public good since it is negative. The term $\int_{0}^{\beta^{m}} \beta H^{\prime}\left(g_{s}^{*}\right) d F$ is included in the modified Samuelson rule since the user charge excludes some of the households from (a part) of the public good. It is positive and tends to an underprovision of the public good. The sum of all three additional terms is unambiguously positive because (11) implies $\alpha-n p(1-F)>0$. This is an alternative proof of the result that tax competition leads to underprovision even in the presence of excludable public good.

In Proposition 3, we have shown that the optimal price on the public good is increasing in the degree of capital mobility. This may be seen as a first indication for the empirical finding that the revenue from user charges has become more important as a source of government revenue. Strictly speaking, however, the empirical evidence presented in the introduction refers to the reliance on user charges. This reliance is defined as the revenue from user charges either as a fraction of total government revenue or as a fraction of government expenditures on the public good which is charged. In our model, both ratios coincide since total revenue equals the expenditures on the (only) public good. Hence, the reliance on user charges may be defined as

$$
\rho^{*}=\frac{n \int_{0}^{\beta^{m}} p^{*} G\left(p^{*}, \beta\right) d F+n p^{*} g_{s}^{*}\left[1-F\left(\beta^{m}\right)\right]}{\alpha g_{s}^{*}} .
$$

On the one hand, an increase in the elasticity of capital exerts a positive effect on $\rho^{*}$ since the optimal price of the public good increases and ceteris paribus leads to a raise in the revenue from the user charge. But on the other hand, the price increase enforces exclusion and reduces the demand of price-excluded households. Both effects ceteris paribus cause a decline in the reliance on user charges. Furthermore, the optimal public 
good supply is reduced as the elasticity of capital increases. This reduces the expenditures on the public good, but also lessens the revenue from the user charge. Several opposing effects therefore determine whether the reliance on user charges increases or decreases in response to a higher capital mobility. However, differentiating (28) with respect to $\varepsilon$ yields

$$
\frac{d \rho^{*}}{d \varepsilon}=\frac{1}{\alpha g_{s}^{*}}\left[n \int_{0}^{\beta^{m}}\left(G+p^{*} G_{p}\right) d F+n g_{s}^{*}\left[1-F\left(\beta^{m}\right)\right]\right] \frac{d p^{*}}{d \varepsilon}-\frac{n p^{*}}{\alpha g_{s}^{* 2}} \int_{0}^{\beta^{m}} G d F \frac{d g_{s}^{*}}{d \varepsilon} .
$$

The bracketed term is positive owing to $L_{p}=0$. From Proposition 3 we know $d p^{*} / d \varepsilon>$ 0 and $d g_{s}^{*} / d \varepsilon<0$. This immediately proves

Proposition 4. Suppose capital is mobile and preferences are quasi-linear. Then $d \rho^{*} / d \varepsilon>0$.

According to Proposition 4, there is an unambiguous effect of tax competition on the reliance on user charges. As capital mobility increases and tax competition becomes fiercer, not only the optimal price on the public good increases, but also does the revenue from the user charge as a fraction of government expenditures. This result is consistent with the empirical findings reported in the introduction.

It should finally be noted that comparative statics with respect to the number of households $(n)$ and the marginal production cost $(\alpha)$ produce few determinate results only. The optimal public good supply can be shown to be increasing in the number of households and decreasing in the marginal production cost. The effects of $n$ and $\alpha$ on all other variables, especially on the reliance on user charges, are indeterminate. Although this result is not very satisfactory from a theoretical point of view, it yet confirms empirical findings. According to Netzer (1992) there is a large variation in the reliance on user charges among US states and among different kinds of public goods, and there is no clear correlation between the reliance on user charges and the size of the state or the production cost of the public goods.

\section{Conclusion}

User charges or user fees are usually justified by externalities like congestion or environmental pollution. This paper presents another explanation for the widespread 
reliance of the state on such charges. It develops a model of a world economy with many identical countries. The government in each country chooses a unit tax on capital and the quantity and price of an excludable public good supplied to heterogeneous households. Under immobile capital, the price on the public good is set equal to zero since the capital tax is lump sum and ensures an efficient supply of the public good. In contrast, under mobile capital each government chooses a positive price since the capital tax becomes a distortionary tax and the countries engage in tax competition. The rationale of this result is that the positive price generates additional revenue which mitigates the underprovision tendencies under tax competition. For the special case of quasi-linear preferences, it turns out that this relation between the optimal price on public goods and tax competition is monotonic and that the reliance on user charges (defined as revenue from the user charges divided by expenditures on public goods) increases as capital mobility is increased and tax competition becomes more intensive. These results are confirmed by the anecdotal evidence from the US which we reported in the introduction. We hope that our analysis stimulates further empirical research on this topic in the US as well as in other countries.

\section{Appendix}

In this appendix we show how a social planner determines the first-best welfare optimum in the representative country. The social planner maximizes welfare subject to the resource constraint and the constraint that the public good consumption of every household must not exceed the public good supply. Her maximization problem is

$$
\max _{\substack{g_{s}, c(\beta), g(\beta) \\ \beta \in[0, \bar{\beta}]}} n \int_{0}^{\bar{\beta}} U[c(\beta), g(\beta), \beta] d F(\beta)
$$

subject to

$$
\begin{gathered}
n \int_{0}^{\bar{\beta}} c(\beta) d F(\beta)+\alpha g_{s}=X(n \bar{k})+n(1+r) \bar{k} \\
g(\beta) \leq g_{s} \quad \text { for all } \quad \beta \in[0, \bar{\beta}]
\end{gathered}
$$


where $c(\beta)$ and $g(\beta)$ are household's $\beta$ consumption of the private and public good, respectively. The resource constraint states that the resources needed to produce the private and the public good must not exceed the total available resources. The Lagrangean of this problem is

$$
\begin{aligned}
L= & n \int_{0}^{\bar{\beta}} U[c(\beta), g(\beta), \beta] d F(\beta)+\theta\left[X(n \bar{k})+n(1+r) \bar{k}-n \int_{0}^{\bar{\beta}} c(\beta) d F(\beta)-\alpha g_{s}\right] \\
& +n \int_{0}^{\bar{\beta}} \psi(\beta)\left[g_{s}-g(\beta)\right] d F(\beta) .
\end{aligned}
$$

The first-order conditions can be written as

$$
\begin{gathered}
-\alpha \theta+n \int_{0}^{\bar{\beta}} \psi(\beta) d F(\beta)=0, \\
U_{g}[c(\beta), g(\beta), \beta]=\psi(\beta) \quad \text { for all } \beta \in[0, \bar{\beta}], \\
U_{c}[c(\beta), g(\beta), \beta]=\theta \quad \text { for all } \quad \beta \in[0, \bar{\beta}], \\
g_{s}-g(\beta) \geq 0, \quad \psi(\beta)\left[g_{s}-g(\beta)\right]=0 \quad \text { for all } \beta \in[0, \bar{\beta}] .
\end{gathered}
$$

Equation (30) implies $\psi(\beta)>0$ which together with $(32)$ yields $g(\beta)=g_{s}$ for all $\beta \in[0, \bar{\beta}]$. Inserting (30) and (31) into (29) gives

$$
n \int_{0}^{\bar{\beta}} \operatorname{MRS}^{q}(\beta) d F(\beta)=\alpha .
$$

Equation (33) is the familiar Samuelson condition. Notice that the marginal utility of the private good has to be the same for all households according to (31).

\section{References}

Blomquist, S. and V. Christiansen (2001), 'The Role of Prices on Excludable Public Goods', CESifo Working Paper No. 956.

Brito, D.L. and W.H. Oakland (1980), 'On the Monopolistic Provision of Excludable Public Goods', American Economic Review 52, 269-304.

Burns, M.E. and C. Walsh (1981), 'Market Provision of Price-Excludable Public Goods', Journal of Political Economy 89, 166-191. 
Calthrop, E. and S. Proost (1998), 'Road Transport Externalities: Interaction Between Theory and Empirical Research', Environmental and Resource Economics 11, 335-348.

Canton, E. (2002), Higher Education Reform: Getting the Incentives Right, CPB Netherlands Bureau for Economic Policy Analysis, The Hague.

Cremer, H. and J.J. Laffont (2003), 'Public Goods with Costly Access', Journal of Public Economics 87, 1985-2012.

Downing, P.B. (1992), 'The Revenue Potential of User Charges in Municipal Finance', Public Finance Quarterly 20, 512-527.

European Commission (2001), White Paper: European Transport Policy for 2010: Time to Decide, Luxembourg.

Fraser, C.D. (1996), 'On the Provision of Excludable Public Goods', Journal of Public Economics 60, 111-130.

Fuest, C., Huber, B. and J. Mintz (2003), 'Capital Mobility and Tax Competition: A Survey', CESifo Working Paper No. 956.

Huber, B. (1999), 'Tax Competition and Tax Coordination in an Optimum Income Tax Model', Journal of Public Economics 71, 441-458.

Mintz, J. and M. Smart (2004), 'Income Shifting, Investment and Tax Competition', Journal of Public Economics 88, 1149-1168.

Netzer, D. (1992), 'Differences in Reliance on User Charges by American State and Local Governments', Public Finance Quarterly 20, 499-511.

Oakland, W.H. (1987), 'Theory of Public Goods', in: Auerbach, A.J. and M. Feldstein (Eds.), Handbook of Public Economics Vol. II, Amsterdam: North-Holland, 485536.

O’Hagan, J. and M.J. Jennings (2003), 'Public Broadcasting in Europe: Rationale, Licence Fee and Other Issues', Journal of Cultural Economics 27, 31-56. 
Schmitz, P.W. (1997), 'Monopolistic Provision of Excludable Public Goods under Private Information', Public Finance 52, 89-101.

Tannenwald, R. (1990), 'Taking Charge: Should New England Increase its reliance on user charges?', New England Economic Review (Jan.Feb.), 56-74.

Wassmer, R.W. and R.C. Fisher (2002), 'Interstate Variation in the Use of Fees to Fund K-12 Public Education', Economics of Education Revenue 21, 87-100.

Wilson, J.D. (1999), 'Theories of Tax Competition', National Tax Journal 52, 269304.

Wilson, J.D. and D.E. Wildasin (2004), 'Capital Tax Competition: Bane or Boon', Journal of Public Economics 88, 1065-1091.

Zodrow, G.R. and P. Mieszkowski (1986), 'Pigou, Tiebout, Property Taxation, and the Underprovision of Local Public Goods', Journal of Urban Economics 19, 356-370. 


\section{CESifo Working Paper Series}

(for full list see www.cesifo.de)

1105 Daniel Haile, Abdolkarim Sadrieh and Harrie A. A. Verbon, Self-Serving Dictators and Economic Growth, December 2003

1106 Panu Poutvaara and Tuomas Takalo, Candidate Quality, December 2003

1107 Peter Friedrich, Joanna Gwiazda and Chang Woon Nam, Development of Local Public Finance in Europe, December 2003

1108 Silke Uebelmesser, Harmonisation of Old-Age Security Within the European Union, December 2003

1109 Stephen Nickell, Employment and Taxes, December 2003

1110 Stephan Sauer and Jan-Egbert Sturm, Using Taylor Rules to Understand ECB Monetary Policy, December 2003

1111 Sascha O. Becker and Mathias Hoffmann, Intra-and International Risk-Sharing in the Short Run and the Long Run, December 2003

1112 George W. Evans and Seppo Honkapohja, The E-Correspondence Principle, January 2004

1113 Volker Nitsch, Have a Break, Have a ... National Currency: When Do Monetary Unions Fall Apart?, January 2004

1114 Panu Poutvaara, Educating Europe, January 2004

1115 Torsten Persson, Gerard Roland, and Guido Tabellini, How Do Electoral Rules Shape Party Structures, Government Coalitions, and Economic Policies? January 2004

1116 Florian Baumann, Volker Meier, and Martin Werding, Transferable Ageing Provisions in Individual Health Insurance Contracts, January 2004

1117 Gianmarco I.P. Ottaviano and Giovanni Peri, The Economic Value of Cultural Diversity: Evidence from US Cities, January 2004

1118 Thorvaldur Gylfason, Monetary and Fiscal Management, Finance, and Growth, January 2004

1119 Hans Degryse and Steven Ongena, The Impact of Competition on Bank Orientation and Specialization, January 2004

1120 Piotr Wdowinski, Determinants of Country Beta Risk in Poland, January 2004 
1121 Margarita Katsimi and Thomas Moutos, Inequality and Redistribution via the Public Provision of Private Goods, January 2004

1122 Martin Peitz and Patrick Waelbroeck, The Effect of Internet Piracy on CD Sales: CrossSection Evidence, January 2004

1123 Ansgar Belke and Friedrich Schneider, Privatization in Austria: Some Theoretical Reasons and First Results About the Privatization Proceeds, January 2004

1124 Chang Woon Nam and Doina Maria Radulescu, Does Debt Maturity Matter for Investment Decisions?, February 2004

1125 Tomer Blumkin and Efraim Sadka, Minimum Wage with Optimal Income Taxation, February 2004

1126 David Parker, The UK's Privatisation Experiment: The Passage of Time Permits a Sober Assessment, February 2004

1127 Henrik Christoffersen and Martin Paldam, Privatization in Denmark, 1980-2002, February 2004

1128 Gregory S. Amacher, Erkki Koskela and Markku Ollikainen, Deforestation, Production Intensity and Land Use under Insecure Property Rights, February 2004

1129 Yin-Wong Cheung, Javier Gardeazabal, and Jesús Vázquez, Exchange Rate Dynamics: Where is the Saddle Path?, February 2004

1130 Alberto Alesina and Guido Tabellini, Bureaucrats or Politicians?, February 2004

1131 Gregory S. Amacher, Erkki Koskela, and Markku Ollikainen, Socially Optimal Royalty Design and Illegal Logging under Alternative Penalty Schemes, February 2004

1132 David M. Newbery, Privatising Network Industries, February 2004

1133 Charles Yuji Horioka, The Stagnation of Household Consumption in Japan, February 2004

1134 Eiji Fujii, Exchange Rate Pass-Through in the Deflationary Japan: How Effective is the Yen's Depreciation for Fighting Deflation?, February 2004

1135 Mark M. Spiegel and Nobuyoshi Yamori, Determinants of Voluntary Bank Disclosure: Evidence from Japanese Shinkin Banks, Febrary 2004

1136 Robert Dekle and Kenneth Kletzer, Deposit Insurance, Regulatory Forbearance and Economic Growth: Implications for the Japanese Banking Crisis, February 2004

1137 Takatoshi Ito and Kimie Harada, Bank Fragility in Japan, 1995-2003, February 2004

1138 Kunio Okina and Shigenori Shiratsuka, Policy Duration Effect under Zero Interest Rates: An Application of Wavelet Analysis, February 2004 
1139 Francine D. Blau and Lawrence M. Kahn, Do Cognitive Test Scores Explain Higher U.S. Wage Inequality?, February 2004

1140 Michael Rauscher, Economic Growth and Tax-Competing Leviathans, February 2004

1141 Ernst Fehr and Jean-Robert Tyran, Money Illusion and Coordination Failure, February 2004

1142 Ingo Vogelsang, Network Utilities in the U.S. - Sector Reforms without Privatization, March 2004

1143 Marc-Andreas Muendler, Estimating Production Functions When Productivity Change is Endogenous, March 2004

1144 Sascha O. Becker, Samuel Bentolila, Ana Fernandes, and Andrea Ichino, Job Insecurity and Children's Emancipation, March 2004

1145 Pascalis Raimondos-Møller and Alan D. Woodland, Non-Preferential Trading Clubs, March 2004

1146 Robert Fenge and Matthias Wrede, EU Regional Policy: Vertical Fiscal Externalities and Matching Grants, March 2004

1147 Chi-Yung Ng and John Whalley, Geographical Extension of Free Trade Zones as Trade Liberalization: A Numerical Simulation Approach, March 2004

1148 Marc-Andreas Muendler, Trade, Technology, and Productivity: A Study of Brazilian Manufacturers, 1986-1998, March 2004

1149 Eugene Beaulieu, Vivek H. Dehejia, and Hazrat-Omar Zakhilwal, International Trade, Labour Turnover, and the Wage Premium: Testing the Bhagwati-Dehejia Hypothesis for Canada, March 2004

1150 Giorgio Brunello and Francesca Gambarotto, Agglomeration Effects on EmployerProvided Training: Evidence from the UK, March 2004

1151 S. Brock Blomberg, Gregory D. Hess, and Athanasios Orphanides, The Macroeconomic Consequences of Terrorism, March 2004

1152 Bodo Sturm and Joachim Weimann, Unilateral Emissions Abatement: An Experiment, March 2004

1153 Wolfgang Ochel, Welfare-to-Work Experiences with Specific Work-First Programmes in Selected Countries, March 2004

1154 Jan K. Brueckner and Eric Pels, European Airline Mergers, Alliance Consolidation, and Consumer Welfare, March 2004

1155 Aaron Tornell, Frank Westermann, and Lorenza Martínez, NAFTA and Mexico's Economic Performance, March 2004 
1156 George Economides, Sarantis Kalyvitis, and Apostolis Philippopoulos, Do Foreign Aid Transfers Distort Incentives and Hurt Growth? Theory and Evidence from 75 Aidrecipient Countries, March 2004

1157 Robert Fenge and Volker Meier, Are Family Allowances and Fertility-related pensions Siamese Twins?, March 2004

1158 Bruno S. Frey, Simon Luechinger, and Alois Stutzer, Valuing Public Goods: The Life Satisfation Approach, March 2004

1159 Jerome L. Stein and Guay C. Lim, Asian Crises: Theory, Evidence, Warning-Signals, March 2004

1160 Romain Ranciere, Aaron Tornell, and Frank Westermann, Crises and Growth: A ReEvaluation, March 2004

1161 Assaf Razin and Efraim Sadka, Transparency, Specialization and FDI, March 2004

1162 Ludger Woessmann, How Equal Are Educational Opportunities? Family Background and Student Achievement in Europe and the United States, March 2004

1163 B.M.S. van Praag and Barbara E. Baarsma, Using Happiness Surveys to Value Intangibles: The Case of Airport Noise, March 2004

1164 Aaron Tornell, Frank Westermann, and Lorenza Martínez, The Positive Link Between Financial Liberalization, Growth, and Crises, March 2004

1165 Helge Berger and Carsten Hefeker, One Country, One Vote? Labor Market Structure and Voting Rights in the ECB, March 2004

1166 Clemens Fuest and Martin Kolmar, A Theory of User-Fee Competition, March 2004

1167 Friedrich Schneider and Robert Klinglmair, Shadow Economies around the World: What Do We Know?, April 2004

1168 Horst Raff and Nicolas Schmitt, Exclusive Dealing and Common Agency in International Markets, April 2004

1169 M. Hashem Pesaran and Allan Timmermann, Real Time Econometrics, April 2004

1170 Sean D. Barrett, Privatisation in Ireland, April 2004

1171 V. Anton Muscatelli, Patrizio Tirelli and Carmine Trecroci, Can Fiscal Policy Help Macroeconomic Stabilisation? Evidence from a New Keynesian Model with Liquidity Constraints, April 2004

1172 Bernd Huber and Marco Runkel, Tax Competition, Excludable Public Goods and User Charges, April 2004 